\title{
Expression of CK-19 in Papillary Thyroid Carcinoma and Its Association with Prognostic Factors - A Cross-Sectional Study
}

\author{
Revathy V.J. ${ }^{1}$, Sarath Kumar A ${ }^{2}$ \\ 1,2 Department of Pathology, Government Medical College, Thiruvananthapuram, Kerala, India.
}

\section{ABSTRACT}

\section{BACKGROUND}

Papillary thyroid carcinomas (PTC) are the most common carcinomas of the thyroid. Diagnosis of PTC is with its distinct nuclear features. Prognosis of PTC is favourable but can also be aggressive as demonstrated by its recurrence. So, we wanted to improve the present diagnostic tools to identify cases with aggressive course. Immunohistochemistry (IHC) markers which are thought to be useful are CK-19 and CD56.

\section{METHODS}

This is a cross sectional study, done in the Department of Pathology, Government Medical College, Thiruvananthapuram from January 2018 to May 2019. Histopathology slides were prepared from 80 samples, IHCs performed, and the data was analysed using statistical software SPSS version 23.0.

\section{RESULTS}

The classic variant was the most common. In the study, predominant population was below 45 years. There was a female predominance and majority of cases had a tumour size of more than $1 \mathrm{~cm} .23 .8 \%$ of the cases showed lymph node metastasis. On evaluating CK-19 expression in PTC, 98.75 \% showed a positive expression, but there was no association between CK-19 expression and factors like age, gender, tumour size, and lymph node metastasis. $96.3 \%$ of cases showed a loss of expression of CD56.

\section{CONCLUSIONS}

Both CK-19 and CD56 can be used together as markers for PTC including all their variants but CK-19 cannot be used to assess the prognosis of PTC as no association was identified in the study between the expression of CK-19 and prognostic factors.

\section{KEY WORDS}

Papillary Thyroid Carcinoma, Immunohistochemistry
Corresponding Author:

Dr. Sarath Kumar,

Associate Professor,

Department of Pathology,

Government Medical College,

Thiruvananthapuram, Kerala, India.

E-mail: sarath_kgmeta@yahoo.com

DOI: $10.14260 / j e m d s / 2021 / 174$

How to Cite This Article:

RevathyVJ, Kumar AS. Expression of CK - 19 in papillary thyroid carcinoma and its association with prognostic factors - a cross-sectional study. J Evolution Med Dent Sci 2021;10(11):813-818, DOI: 10.14260/jemds/2021/174

Submission 30-11-2020,

Peer Review 20-01-2021,

Acceptance 27-01-2021,

Published 15-03-2021.

Copyright (C) 2021 Revathy V. J. et al. This is an open access article distributed under Creative Commons Attribution License [Attribution 4.0 International (CC BY 4.0)] 


\section{BACKGROUND}

Papillary thyroid carcinomas are the most common carcinomas of the thyroid. ${ }^{1}$ In recent decades an obvious increase in the incidence of papillary thyroid carcinoma has occurred. ${ }^{1}$ Gold standard for diagnosis of PTC is histological evaluation. ${ }^{2,3}$ Diagnosis of papillary thyroid carcinoma, in many but not all cases, is an easily achievable diagnosis with its distinct nuclear features, with almost minimal interobservable variability between pathologists. As with thyroid carcinomas in general, prognosis of PTC is favourable, usually for classical subtype of PTC. ${ }^{4}$ They can also be aggressive as demonstrated by the recurrence of the disease. ${ }^{4,5}$ So, wanted to improve the present diagnostic tools to find out the cases with aggressive course. Besides haematoxylin and eosin staining for evaluating thyroid tumour morphology, immunohistochemical methods have been widely used. Two such IHC markers which are thought to be useful are CK 19 and CD 56.

Cytokeratins (CK) are keratin proteins found in the intracytoplasmic cytoskeleton of epithelial tissue. ${ }^{6}$ Cytokeratin 19 is a type 1 keratin. In thyroid gland, normal follicular epithelium usually has no detectable CK19 expression. ${ }^{6}$ Strong and diffuse staining of CK19 expression was noted in most of the papillary carcinoma thyroid in previous studies.

CD56 is a neural cell adhesion molecule (NCAM), which has a role in cell adhesion. ${ }^{7}$ CD56 is present on follicular epithelial cells of normal thyroid 8,9 and show diffuse membranous positivity. Previous studies show low or absent expression in all variants of papillary carcinoma thyroid.

Most common subtypes of PTC include the classic, follicular and tall cell variants. ${ }^{10}$ Many other uncommon variants like oncocytic, columnar cell, diffuse sclerosing and solid forms, clear cell and cribriform morular variant have also been described. ${ }^{10}$ There are many clinical and pathological factors that are associated with the poor prognosis of papillary carcinoma, which includes age, gender, distant metastasis, size of the primary tumour, subtypes and lymph node involvement. 4,10

Our objective was to assess the expression of CK19 in papillary thyroid carcinoma and to find its association with few of these prognostic parameters like age, gender, tumour size and metastasis to lymph nodes. Also, to study the expression of CD56 in papillary thyroid carcinoma. The association between CK19 expression and the patient's unfavourable prognostic factors could suggest its possible role as a marker of poor prognosis of PTC.

\section{METHODS}

This cross-sectional study was conducted from January 2018 to May 2019 in the Department of Pathology, Government Medical College, Thiruvananthapuram, Kerala. Human ethics committee approval was obtained on 19 / 12 / 2017 (IEC.No. 15 / 16 / 2017 / MCT)

The cases included for the study were histopathologically proven cases of papillary thyroid carcinoma and its variants from thyroidectomy specimens received in Department of Pathology. Cases without proper data were excluded. It was a record-based study.

\section{Sample Size}

Minimum sample size for the study is calculated using the formula,

Sample size, $\mathrm{n}=\frac{4 \mathrm{PQ}}{\mathrm{D}^{2}}$

$\mathrm{P}=$ Population proportion of factor under study, $\mathrm{P}=81$ (taken from previous study conducted by Talaat et al). ${ }^{7}$

$\mathrm{Q}=100-\mathrm{P}$

$\mathrm{D}=$ Maximum variability that can be afforded (taken as $20 \%$ of P)

$\mathrm{N}=\rightarrow \frac{4 \times 81 \times 19}{16.2 \times 16.2} \rightarrow=23.45$

Minimum sample size, $\mathrm{N}=24$

For association, as 3 factors are used, 10 cases added for each factor. So, sample size $=54$. We took 80 samples for the study.

\section{Sampling Method}

First 80 consecutive specimens meeting the inclusion and exclusion criteria during the period of analysis were included in the study.

\section{Study Tool}

1. Instruments to take bits of tissue to be studied.

2. Reagents for tissue processing.

3. Instruments for making paraffin blocks and cutting thin sections from it.

4. Haematoxylin and eosin (H \& E) stains.

5. Glass slides and cover slips for mounting.

6. Microscope.

7. IHC markers CD56 and CK-19.

8. A structured proforma to record patient details: name, age, sex, inpatient number, histopathology report number, type of surgery, tumour size and metastasis and diagnosis made.

\section{Data Collection Technique}

A structured proforma was used to collect data of the selected cases and its prognostic factors.

Surgically resected thyroid tissues were fixed in $10 \%$ neutral buffered formalin. Specimens were then grossed, and adequate samples were taken from appropriate area and then processed in automated tissue processing unit. After processing, tissues are embedded in paraffin wax and are then made into blocks for taking sections. Sections of 4 - 5 micrometre thickness are cut from the blocks and stained with haematoxylin and eosin staining. The slides are analysed under optical microscope and diagnosis were entered in the proforma.

Blocks of those slides showing tumour were collected. Unstained slides are made from them. Thinner sections are taken on aminopropyltriethoxysilane (APES) coated slides 
and incubated overnight for adequate fixation. Immunostaining for CD56 and CK-19 was done in our immunohistochemistry laboratory following standard IHC protocol. The stained slides were then mounted and labelled. Interpretation of CK-19 and CD56 were done and results entered as positive or negative. The procedures and evaluation were done by single observer.

\section{Immunohistochemical Evaluation}

A positive cytoplasmic expression in $10 \%$ or more of the cells was regarded as positive for CK-19.

A positive membranous expression with or without cytoplasmic staining in $10 \%$ or more of the cells were taken as positive expression for CD56. Less than $10 \%$ as well as no expression is taken as negative.

The expression of CK-19 and CD56 in papillary thyroid carcinoma was compared with the surrounding thyroid tissue to assess the gain or loss of expression.

For each antibody, immunoreactivity is scored as;

- $\quad$ Negative (- ve: less than $10 \%)$,

- Focally positive (+: less than $25 \%$ ),

- Positive (++: 25 - $50 \%)$

- Diffusely positive (+++: more than $50 \%$ ) based on extent of reaction. ${ }^{11}$

\section{Statistical Analysis}

All collected data was entered in Microsoft Excel sheet with all relevant details and analysed using statistical software SPSS version 23.0. The qualitative variables were expressed in percentage. The association was tested using appropriate statistical test.

\section{RESULTS}

\section{Age Distribution}

The age ranges from 7 years to 75 years. 47 cases were in the age group less than or equal to 45 years and 33 cases were in the age group above 45 years. Higher percentage of papillary carcinoma was identified in the age group less than 45 years (58.8\%).

\section{Gender Distribution}

Among 80 cases, 69 were female patients and 11 were males, with a female predominance of $86.3 \%$.

\section{Variants of Papillary Thyroid Carcinoma}

The variants of papillary carcinoma thyroid included were classic variant PTC, follicular variant PTC, tall cell variant, columnar cell variant and Warthin like variant. Of which, classic variant predominates with a percentage of $81.3 \% .12$ cases of follicular variant PTC were collected constituting 15 $\%$ and one case each for tall cell, columnar cell and Warthin like variants constituting $1.3 \%$ each.

\section{Size Distribution}

Comparing the size of PTC, the cases were grouped into $\leq 1$ $\mathrm{cm}$ and $>1 \mathrm{~cm}$. Majority of cases were more than $1 \mathrm{~cm}$ that accounts for $85 \%$ of cases.

\section{Distribution of Cases with Lymph Node Metastasis}

Of the total 80 cases of PTC, lymph node metastasis was noted in 19 cases that constituted $23.8 \%$, of which 1 case was follicular variant of PTC and all others were classic variant of PTC.

\section{CK-19 in Papillary Thyroid Carcinoma}

Out of 80 cases of PTC, 79 cases (98.8\%) showed $3+$ or $4+$ cytoplasmic and membranous positivity for CK19 and only 1 case showed a negative expression. 5 out of 12 cases of follicular variant showed a $3+$ positivity, whereas columnar cell variant, tall cell variant and Warthin like variant showed $4+$ positivity.

\section{CD56 in Papillary Thyroid Carcinoma}

Of the 80 cases of papillary thyroid carcinoma, 77 cases were negative for CD56 expression that accounts for $96.3 \%$. 3 cases showed a $2+$ positivity, but still there was a loss of expression when compared to the surrounding normal thyroid. We observed a diffuse CD56 staining reaction with distinctive membranous pattern in the normal thyroid.

\section{Association of CK-19 Expression with Prognostic Factors}

Statistical analysis of the data obtained is done by using SPSS software 23.0. Fisher's exact test was done to find out the association between CK-19 expression and prognostic factors of PTC like age, gender, tumour size and lymph node metastasis. The result of statistical analysis are as follows -

\section{Comparison of Age and CK-19 Expression}

The association between CK-19 expression and age of the patients was studied. Out of 47 cases whose age is less than or equal to 45 years, 46 cases showed $3+$ or $4+$ positivity for CK-19 (97.9\%) and 1 case showed a negative expression. And all the 33 cases who were in the age group above 45 years also showed positive expression for CK-19 (100\%). (Table 1)

CK-19 expression and age of patients does not have a statistically significant relationship as the $\mathrm{P}$-value is $>0.05$ (0.587)

\begin{tabular}{|cccccc|}
\hline \multirow{2}{*}{ Age } & \multicolumn{2}{c}{ Positive } & \multicolumn{2}{c|}{ Negative } & \multirow{2}{*}{ P\# } \\
< = 45 Yrs. & 46 & 97.9 & 1 & 2.1 & \multirow{2}{*}{0.587} \\
> 45 Yrs. & 33 & 100.0 & 0 & 0.0 & \\
\hline \multicolumn{5}{r}{ Table 1. Comparison of Age Based on CK-19 Expression } \\
\hline \#: Fisher's exact test & Percent & Count & Percent & \\
\hline
\end{tabular}



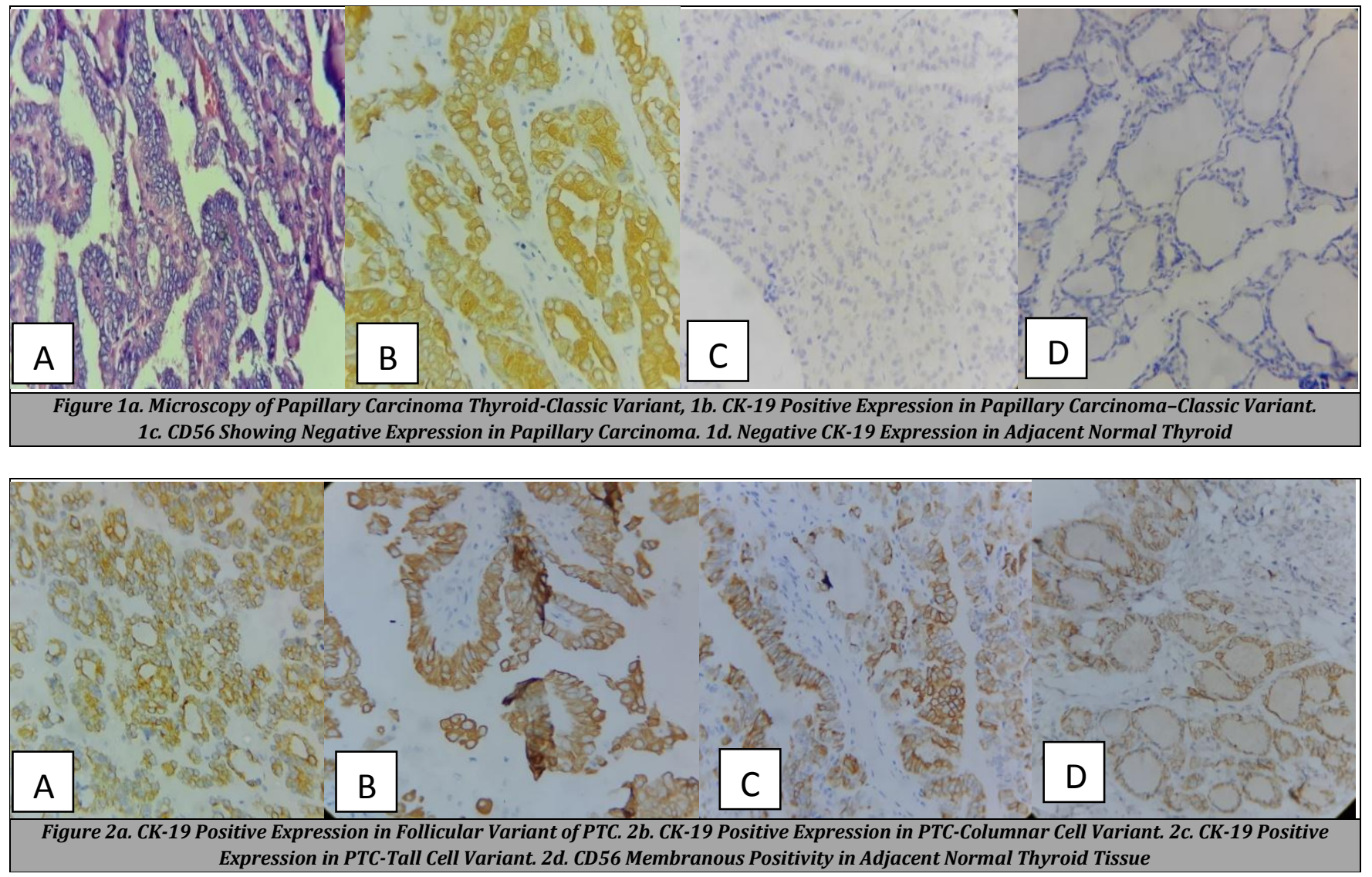

\section{Comparison of Gender and CK-19 Expression}

The association between CK-19 expression and gender of the patients was studied. Out of 69 females, 68 cases (98.6\%) showed a positivity for CK-19 expression and 1 case $(1.4 \%)$ was negative. All the 11 cases who were male patients were positive (100\%) for CK-19 expression.

From the statistical analysis, CK-19 expression and gender of the patient does not have a statistically significant relationship as the P-value was $>0.05$ (0.862) (Table 2)

\begin{tabular}{|cccccc|}
\hline \multirow{2}{*}{ Gender } & \multicolumn{2}{c}{ Positive } & \multicolumn{2}{c|}{ Negative } & \multirow{2}{*}{ P\# } \\
& Count & Percent & Count & Percent & \\
Female & 68 & 98.6 & 1 & 1.4 & 0.862 \\
Male & 11 & 100.0 & 0 & 0.0 & \\
\hline \multicolumn{7}{r}{ Table } & 2. Comparison of Gender Based on CK-19 Expression \\
\hline \#: Fisher's exact test
\end{tabular}

\section{Comparison of Tumour Size and CK-19 Expression}

The association between tumour size and CK-19 expression was studied. Of the 68 cases which was more than $1 \mathrm{~cm}$ in size, 67 cases (98.5\%) showed positivity for CK-19 expression and 1 case showed a negative expression. All the 12 cases of PTC which was less than or equal to $1 \mathrm{~cm}$ in size showed positive CK-19 expression (100\%).

CK-19 expression and size of the tumour does not have a statistically significant relationship as the P-value is $>0.05$ (0.850) (Table 3).

\begin{tabular}{|cccccc|}
\hline \multirow{2}{*}{ Size } & \multicolumn{2}{c}{ Positive } & \multicolumn{2}{c|}{ Negative } & \multirow{2}{*}{ P\# } \\
& Count & Percent & Count & Percent & \\
$<=1 \mathrm{~cm}$ & 12 & 100.0 & 0 & 0.0 & 0.850 \\
$>1 \mathrm{~cm}$ & 67 & 98.5 & 1 & 1.5 & \\
\hline \multicolumn{4}{r}{ Table } & 3. Comparison of Size & Based on \\
CK-19 Expression \\
\hline \#: Fisher's exact test
\end{tabular}

Comparison of Cases with Lymph Node Metastasis and CK-19 Expression

The association between CK-19 expression and lymph node metastasis was studied. Out of 19 cases with lymph node metastasis, 18 cases (94.7 \%) showed a CK-19 positive expression, and 1 case showed a negative expression (5.3\%). All the 61 cases without lymph node metastasis also showed a positive CK 19 expression (100 \%)

CK19 expression and the lymph node status of the patient does not have a statistically significant relationship as the $P$ value is $>0.05(0.237)$ (Table 4$)$

\begin{tabular}{|c|c|c|c|c|c|}
\hline \multirow{2}{*}{$\begin{array}{l}\text { Lymph Node } \\
\text { Mets }\end{array}$} & \multicolumn{2}{|c|}{ Positive } & \multicolumn{2}{|c|}{ Negative } & \multirow{2}{*}{ P\# } \\
\hline & Count & Percent & Count & Percent & \\
\hline Present & 18 & 94.7 & 1 & 5.3 & \multirow{2}{*}{0.237} \\
\hline Absent & 61 & 100.0 & 0 & 0.0 & \\
\hline \multicolumn{6}{|c|}{$\begin{array}{c}\text { Table 4. Comparison of Lymph Node Metastasis } \\
\text { Based on CK-19 Expression }\end{array}$} \\
\hline \#: Fisher's exact & & & & & \\
\hline
\end{tabular}

\section{DISCUSSION}

Present study included 80 total thyroidectomy cases diagnosed as papillary thyroid carcinoma. Out of 80 cases most of the cases were in the age group less than 45 years and with a female preponderance. Primary objective was to study the expression of CK-19 in papillary thyroid carcinoma and to study the association between its expression and the prognostic factors of PTC.

Comparing the age group with other studies, Kaliszewski et al. ${ }^{4}$ Zeming et al. ${ }^{12}$ and Sook et al. ${ }^{13}$ showed majority of cases were in the age group more than 45 years. All these 
studies showed a female preponderance which is similar to the present study. This difference in the age group when comparing with the previous studies may be due to a rise in ultrasonography (USG) and cytology studies and regarding the health concern in younger population leading to increase in health check-ups.

The most common variant of papillary thyroid carcinoma obtained in the present study was classic variant, followed by follicular variant. Similar studies done by Sooket al. ${ }^{13}$ and many other studies showed common type as the classic variant followed by follicular variant.

Regarding the size of the tumour, present studies shows predominantly size more than $1 \mathrm{~cm}$ and study conducted by Kaliszewski et al. ${ }^{4}$ also showed that the predominant cases in their study were more than $1 \mathrm{~cm}$ in size, whereas study conducted by Zeming et al. ${ }^{12}$ and Sook et al. ${ }^{13}$ showed that the predominant population in their study were showing a size less than or equal to $1 \mathrm{~cm}$.

Present study showed a lymph node metastasis in $23.8 \%$ of cases and the studies conducted by Kaliszewski et al ${ }^{4}$ showed lymph node metastasis in $26.1 \%$ of cases and study conducted by Zeming et al.12 showed $30.5 \%$ cases with lymph node metastasis which is comparable with our study. The previous studies showed the lymph node metastasis were predominantly seen in the classic variant of PTC similar to present study.

Regarding CK-19 expression, $98.75 \%$ of cases showed a CK-19 positivity in the present study and it was comparable with the previous studies. The study conducted by Bose et al. ${ }^{14}$ and another study conducted by Gong et al. ${ }^{11}$ showed a $100 \%$ positive expression for CK-19 expression and Dina et al. ${ }^{1}$ showed $85 \%$ positivity for CK-19 expression in papillary carcinoma thyroid.

Comparing the CK-19 expression with the prognostic factors like age, gender, tumour size and lymph node metastasis, no significant relationship was identified in the present study whereas, study conducted by Zeming et al.12 showed a significant relation of CK-19 expression with tumour size and not with any other prognostic factors. Kalisweski et al. ${ }^{4}$ showed a significant relation of CK-19 expression with only recurrent cases and not with any other prognostic factors like age, gender, tumour size and lymph node metastasis.

\begin{tabular}{|c|c|c|c|}
\hline Prognostic Factors & $\begin{array}{c}\text { Zeming et al. } \\
\text { (P-Value) }\end{array}$ & $\begin{array}{c}\text { Kalisweski et al. } \\
\text { (P-Value) }\end{array}$ & $\begin{array}{c}\text { Present Study } \\
\text { (P-Value) }\end{array}$ \\
\hline Age & 1.000 & 0.494 & 0.587 \\
\hline Gender & 0.161 & 0.340 & 0.862 \\
\hline Tumour size & 0.017 & 0.505 & 0.850 \\
\hline Lymph node metastasis & 0.171 & 0.494 & 0.237 \\
\hline \multicolumn{4}{|c|}{ Table 5. Comparison of P-Value Calculated } \\
\hline
\end{tabular}

The secondary objective was to study the expression of CD56 in papillary thyroid carcinoma. Present study showed $96.3 \%$ loss of CD56 expression in papillary thyroid carcinoma in the center as well as periphery of the tumour including all its variants except for 3 cases of classic variant that showed $2+$ positivity.

The study conducted by Dusko et al. ${ }^{15}$ showed a similar observation with a $100 \%$ loss of expression of CD56 and study conducted by Demellawy et al. ${ }^{1}$ also showed $100 \%$ loss of expression of CD56.

\section{CONCLUSIONS}

Among PTC cases, classic variant of PTC was the most common. The predominant population was below 45 years of age and there was a female predominance. Majority had a tumour size of more than $1 \mathrm{~cm} .23 .8 \%$ of cases showed lymph node metastasis. $98.75 \%$ showed a positive CK-19 expression, but there was no association between CK-19 expression and factors like age, gender, tumour size, and lymph node metastasis. $96.3 \%$ of cases showed loss of expression of CD56.

Through this study it is concluded that, both CK-19 and CD56 can be used together as markers for PTC including all its variants but CK-19 cannot be used to assess the prognosis of papillary thyroid carcinoma as no association was identified in the study between the expression of CK-19 and prognostic factors.

Data sharing statement provided by the authors is available with the full text of this article at jemds.com.

Financial or other competing interests: None.

Disclosure forms provided by the authors are available with the full text of this article at jemds.com.

\section{REFERENCES}

[1] El Demellawy D, Nasr A, Alowami S. Application of CD56, P63 and CK19 immunohistochemistry in the diagnosis of papillary carcinoma of the thyroid. Diagn Pathol 2008;3(1):5.

[2] Erdogan-Durmus S, Ozcan D, Yarikkaya E, et al. CD56, HBME-1 and cytokeratin 19 expressions in papillary thyroid carcinoma and nodular thyroid lesions. J Res Med Sci 2016;21:49.

[3] $\mathrm{Ma} \mathrm{H}, \mathrm{Xu} \mathrm{S,} \mathrm{Yan} \mathrm{J,} \mathrm{et} \mathrm{al.} \mathrm{The} \mathrm{value} \mathrm{of} \mathrm{tumor} \mathrm{markers} \mathrm{in} \mathrm{the}$ diagnosis of papillary thyroid carcinoma alone and in combination. Pol J Pathol 2014;65(3):202-9.

[4] Kaliszewski K, Diakowska D, Strutynska-Karpinska M, et al. Expression of cytokeratin - 19 (CK19) in the classical subtype of papillary thyroid carcinoma: the experience of one center in the Silesian region. Folia Histochem Cytobiol 2016;54(4):193-201.

[5] Sadow PM, Hunt JL. Update on clinically important variants of papillary thyroid carcinoma. Diagnostic Histopathol 2011;17(3):106-13.

[6] Liu Z, Li X, Shi L, et al. Cytokeratin 19, thyroperoxidase, HBME-1 and galectin-3 in evaluation of aggressive behavior of papillary thyroid carcinoma. Int J Clin Exp Med 2014;7(8):2304-8.

[7] Abouhashem NS, Talaat SM. Diagnostic utility of CK19 and CD56 in the differentiation of thyroid papillary carcinoma from its mimics. Pathol Res Pract 2017;213(5):509-17.

[8] Golu I, Vlad MM, Dema A, et al. The absence of CD56 expression can differentiate papillary thyroid carcinoma from other thyroid lesions. Indian J Pathol Microbiol 2017;60(2):161-6. 
[9] Mokhtari M, Eftekhari M, Tahririan R. Absent CD56 expression in papillary thyroid carcinoma: a finding of potential diagnostic value in problematic cases of thyroid pathology. J Res Med Sci 2013;18(12):1046-50.

[10] Sak SD. Variants of papillary thyroid carcinoma: multiple faces of a familiar tumor. Turk Patoloji Derg 2015;31(Suppl 1):34-47.

[11] Gong L, Chen P, Liu X, et al. Expressions of D2-40, CK19, galectin-3, VEGF and EGFR in papillary thyroid carcinoma. Gland Surg 2012;1(1):25-32.

[12] Liu Z, Zeng W, Chen T, et al. A comparison of the clinicopathological features and prognoses of the classical and tall cell variant of papillary thyroid cancer: a meta analysis. Oncotarget 2017;8(4):6222-32.
[13] Min HS, Lee C, Jung KC. Correlation of immunohistochemical markers and BRAF mutation status with histological variants of papillary thyroid carcinoma in the Korean population. J Korean Med Sci 2013;28(4):534-41.

[14] Bose D, Das RN, Chatterjee U, et al. Cytokeratin 19 immunoreactivity in the diagnosis of papillary thyroid carcinoma. Indian J Med Paediatr Oncol 2012;33(2):10711.

[15] Dunderović D, Lipkovski JM, Boričic I, et al. Defining the value of CD56, CK19, galectin 3 and HBME-1 in diagnosis of follicular cell derived lesions of thyroid with systematic review of literature. Diagn Pathol 2015;10:196. 